Article

\title{
Performance Evaluation of Carbon Black Nano-Particle Reinforced Asphalt Mixture
}

\author{
Javaria Rafi* (1), Mumtaz Ahmed Kamal, Naveed Ahmad, Murryam Hafeez, \\ Muhammad Faizan ul Haq, Syeda Aamara Asif, Faisal Shabbir and Syed Bilal Ahmed Zaidi \\ Department of Civil Engineering, University of Engineering and Technology Taxila, Taxila 47080, Pakistan; \\ dr.kamal@uettaxila.edu.pk (M.A.K.); n.ahmad@uettaxila.edu.pk (N.A.); murryamhafeez77@outlook.com (M.H.); \\ faizan.ul@students.uettaxila.edu.pk (M.F.u.H.); amara.asifshah@yahoo.com (S.A.A.); \\ faisal.shabbir@uettaxila.edu.pk (F.S.); bilal.zaidi@uettaxila.edu.pk (S.B.A.Z.) \\ * Correspondence: javariarafi@outlook.com; Tel.: +92-3476878275
}

Received: 24 May 2018; Accepted: 6 July 2018; Published: 10 July 2018

\begin{abstract}
Applications of nanotechnology in the pavement industry have increased rapidly during the last decade in order to enhance a pavement's sustainability and durability. Conventional asphalt binder generally does not provide sufficient resistance against rutting at high temperatures. Carbon black nano-particles (CBNPs, produced by perennial mountain trees' carbonization) were mixed into the performance grade (PG) 58 asphalt binder in this study. Conventional asphalt binder tests (penetration, ductility and softening point), frequency sweep, performance grading, and bitumen bond strength tests were conducted to study the enhancement in the properties of asphalt binder. Dynamic modulus and wheel tracking tests were also performed to investigate the effect of CBNPs on asphalt mixture properties. Experimental results demonstrated that preferred dosage of CBNPs in asphalt is $10 \%$ by weight of the bitumen. Results of scanning electron microscopy (SEM) and storage stability tests validated homogenous and stable dispersion of CBNPs in the asphalt binder. Asphalt mixtures became stiffer and resistant to rutting at high temperatures by addition of CBNPs in asphalt binder. Significant improvement in bitumen aggregate bond strength was also observed by incorporating CBNPs. It is concluded that CBNPs can be used to effectively enhance the high-temperature performance and consequently the sustainability of flexible pavements.
\end{abstract}

Keywords: carbon black nano-particles (CBNPs); asphalt binder; performance grading; scanning electron microscopy (SEM); dynamic modulus; rutting

\section{Introduction}

Poor flexible pavement performance at high temperatures is the major problem that is faced by the pavement industry in Pakistan. Asphalt pavements in the country fail prematurely because of mix rutting. Mix rutting is observed only in the high-temperature areas of the country. The lower softening point values of the locally produced unmodified binders make them susceptible to rutting during the summers. The other most commonly faced distress in the country is the moisture damage of the asphaltic pavements especially during the rainfall/monsoon season.

Pavement engineers are always in search of modifiers that could not only improve the rheological properties of the binders but could also concurrently enhance their adhesion capabilities. Asphalt mixtures have been modified in the past by carbonaceous materials, as they are believed to be intrinsically compatible with the asphalt mixture [1]. Among the carbonaceous materials, different researchers have utilized carbon black because of its easy availability. It has been learnt that high dosages of carbon black in asphalt can increase the rutting resistance and lessen the temperature susceptibility [2-11]. It is also said that the performance of carbon black depends upon its structure, 
particle size and surface area [12,13]. Nanotechnology is an emerging field and is extensively used by pavement engineers worldwide. Different types of carbon black nano-particles (CBNPs) have been manufactured and incorporated to modify asphalt properties [14-16] but, to the authors' best knowledge, the one made with natural sources has never been used by pavement engineers. The selected CBNPs come from a natural source and their effect on the rheology of the modified binder, bitumen-aggregate adhesion, and moisture susceptibility needs to be investigated.

The pavement industry in Pakistan is still using penetration grading for bitumen selection while the rest of the world is fast adopting the latest performance grading (PG). Performance grading is based on the concept that the properties of the asphalt binder should be related to the conditions under which it is used. According to temperature zoning done by Mirza et al. [17], PG 70-10 would be sufficient for most parts of the country. Base asphalt binder generally used in the country has PG 58-22 which is softer than the required PG 70-10. As mentioned earlier, the problematic areas are only the high temperature areas of the country where, even in winters, temperatures hardly fall below $0{ }^{\circ} \mathrm{C}$. Therefore, high PG values are of more concern and the main aim is to use a dosage of nano-material that would help achieve the $70{ }^{\circ} \mathrm{C}$ threshold.

The paper aims to investigate the effect of CBNPs $(150 \mathrm{~nm})$ produced by perennial mountain trees' carbonization on the rheological properties of asphalt binder, aggregate and asphalt binder bond strength, and rutting resistance of asphalt.

\section{Experimental Work}

\subsection{Materials}

\section{Aggregates}

Aggregates (limestone) used in this study were procured from Margalla in Punjab, Pakistan. Different material properties of Margalla aggregates are displayed in the Table 1.

Table 1. Margalla aggregates material properties [18].

\begin{tabular}{ccc}
\hline Material Properties & Percent (\%) & Recommended Range by NHA * \\
\hline Fractured particles & 100 & $90 \%(\min )$ \\
Flakiness & 5 & $10 \%(\max )$ \\
Elongation & 11 & $10 \%(\max )$ \\
Sand equivalent & 75 & $50 \%(\min )$ \\
Los Angeles abrasion & 15 & $15 \%(\max )$ \\
Water absorption & 1.02 & $2 \%(\max )$ \\
Soundness (Coarse) & 7.1 & $8 \%(\max )$ \\
Soundness (Fine) & 4.7 & $8 \%(\max )$ \\
Uncompacted voids & 37.5 & $45 \%(\min )$ \\
\hline \multicolumn{2}{c}{$*$ National Highway Authority of Pakistan. }
\end{tabular}

\section{Bitumen}

In this study, 60/70 penetration bitumen was used. It was obtained from Attock Oil Refinery Limited (ARL) which is the most commonly used source for bitumen procurement in Pakistan.

\section{Carbon Black Nano-Particles (CBNPs)}

Carbon black nano-particles (stock \# US1067) procured from US Research Nanomaterials, Inc. (Houston, TX 77084, USA) were used in this study. These are produced by carbonization and extreme fine grinding of perennial trees at high temperature of up to $1300^{\circ} \mathrm{C}$. Features of procured CBNPs are shown in Table 2. 
Table 2. Carbon black nano-particles (CBNPs) feature.

\begin{tabular}{cc}
\hline Morphology & Spherical \\
\hline Colour & Black \\
Purity & Greater than $95 \%$ \\
Average particle size (APS) & $150 \mathrm{~nm}$ \\
$\mathbf{H}_{\mathbf{2}} \mathbf{O}$ & Less than $5 \%$ \\
Ash & Less than $3.2 \%$ \\
PH & 9.8 \\
Density & $0.38 \mathrm{~g} / \mathrm{mL}$ \\
Electrical Resistivity & $0.30 \Omega \cdot \mathrm{cm}$ \\
\hline
\end{tabular}

\subsection{Preparation of CBNPs Modified Bitumen}

Two percentages of CBNPs were used in this study i.e., $5 \%$ and $10 \%$ by weight of asphalt binder. The maximum CBNPs content of $10 \%$ was selected, as performance grade (PG) 70 was achieved at this dosage. PG 70 is the desired performance grade of binder in Pakistan as per the temperature zoning [17]. PG 70-10 asphalt binder covers almost 70\% areas of Pakistan. Asphalt binder (60/70) procured from Attock Oil Refinery has PG 58-22, therefore CBNPs were mixed with the asphalt binder to achieve the desired performance grade. All modified binders were prepared using a high shear mixer. Asphalt binder was heated to $158 \pm 5^{\circ} \mathrm{C}$ until it became fluid. Then CBNPs were added steadily into the asphalt binder and the mixture was stirred at $2800 \mathrm{rpm}$ for $45 \mathrm{~min}$ to ensure homogenous dispersion of nanoparticles. Scanning electron microscopy (SEM) was used to check the homogenous dispersion of CBNPs in the asphalt binder. Figure 1a shows the spherical shape of CBNPs used in this study whereas homogenous dispersion of CBNPs in the asphalt binder is displayed in Figure $1 \mathrm{~b}$. Figure $1 \mathrm{~b}$ depicts that the mixing operation of applying $2800 \mathrm{rpm}$ for $45 \mathrm{~min}$ to disperse CBNPs in the asphalt binder is acceptable.

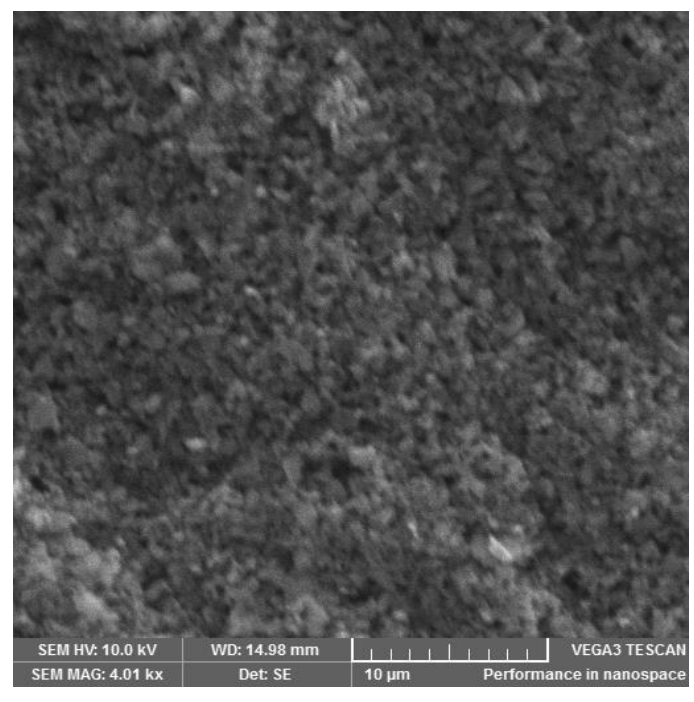

(a)

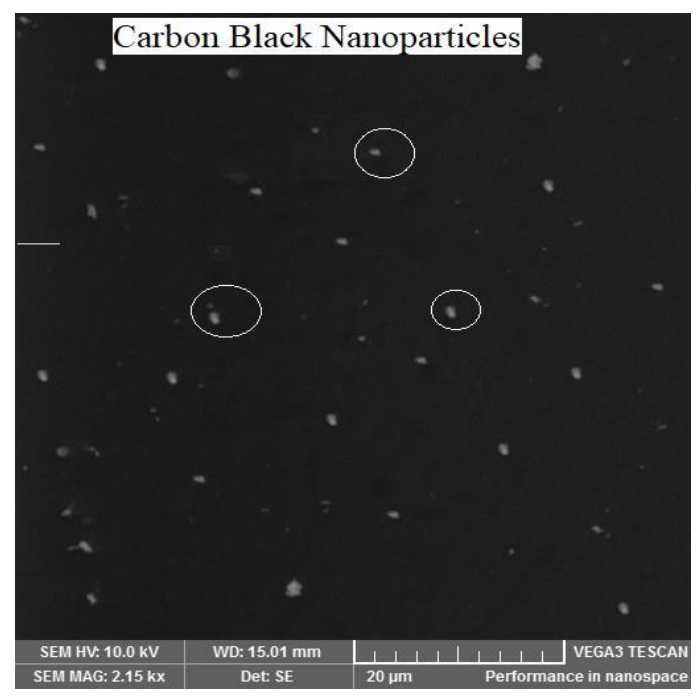

(b)

Figure 1. (a) Scanning electron microscope (SEM) image of carbon black nano-particles (CBNPs); (b) SEM image of carbon black nano-particles in asphalt binder.

Homogenous dispersion was further ensured by storage stability analysis and repeatable results of PG during trial blending techniques. The storage stability analysis (BS EN 13399-2017) of CBNPs modified samples showed less than $2.5^{\circ} \mathrm{C}$ difference in softening point among the top and bottom portions of the sample, which is proof of stable and homogenous CBNPs-modified asphalt binder. 
A number of CBNPs-modified binder samples were prepared by using different mixing durations and blending techniques (hand mixing, and shear mixing utilizing different blender RPMs). All these samples were tested under dynamic shear rheometer (DSR) and their high PG temperatures were determined. Mixing duration of $45 \mathrm{~min}$ and 2800 blender RPMs were finally selected as these two conditions provided with a homogeneous sample with repeatable results. DSR test results for the samples that were taken from three different portions of the sample container (top, bottom, and middle) during PG test also provides proof of homogenous dispersion of CBNPs in the asphalt binder. Results are presented in Table 3.

Table 3. Performance grades showing homogeneous dispersion.

\begin{tabular}{ccc}
\hline Sample Container & $\mathbf{5 \%}$ CBNPs & $\mathbf{1 0 \%}$ CBNPs \\
\hline Top Portion & PG 64 $\left(64.5^{\circ} \mathrm{C}\right)$ & PG 70 $\left(71.0^{\circ} \mathrm{C}\right)$ \\
Middle Portion & PG 64 $\left(64.2^{\circ} \mathrm{C}\right)$ & PG $70\left(70.9^{\circ} \mathrm{C}\right)$ \\
Bottom Portion & PG $64\left(64.7^{\circ} \mathrm{C}\right)$ & PG $70\left(70.6^{\circ} \mathrm{C}\right)$ \\
\hline
\end{tabular}

The traceability of particles through SEM is largely related to the size of the particles. As the utilized CBNPs had an average diameter of $150 \mathrm{~nm}$, they were relatively easily traceable. However, some trials were still required to be carried out, and it was necessary to zoom-in to the required resolution to study the dispersion of CBNPs in bitumen. SEM is generally sufficient to study the dispersion of particles [19], however, for more in depth analysis into the size and internal structure of the particles, transmission electron microscopy (TEM) may be preferred.

\subsection{Preparation of Asphalt Mixtures}

Midpoint aggregate gradation of National Highway Authority (NHA) class B (19.5 mm nominal maximum aggregate size) was used in this study. It is specified as a finer gradation and is generally used by the local pavement industry as an asphalt wearing course. The midpoint gradation curve for NHA class B is shown in Figure 2. Marshall mix design was performed for two CBNPs percentages ( $5 \%$ and $10 \%$ by weight of asphalt binder) to get the optimum binder content for asphalt mix design. In this test, a standard hammer of $4.5 \mathrm{lbs}$ was used and it was dropped from 18 in height; 75 blows of the hammer were applied on each side of the specimen (specified for heavy traffic in the specifications of the Asphalt Institute). Midpoint of the in-place air voids range (3 to 8 percent) as specified in MS-2 series, i.e., $5.5 \%$ of air voids were maintained in the design. Optimum bitumen contents for the two CBNPs percentages used in asphalt performance testing are shown in the Table 4.

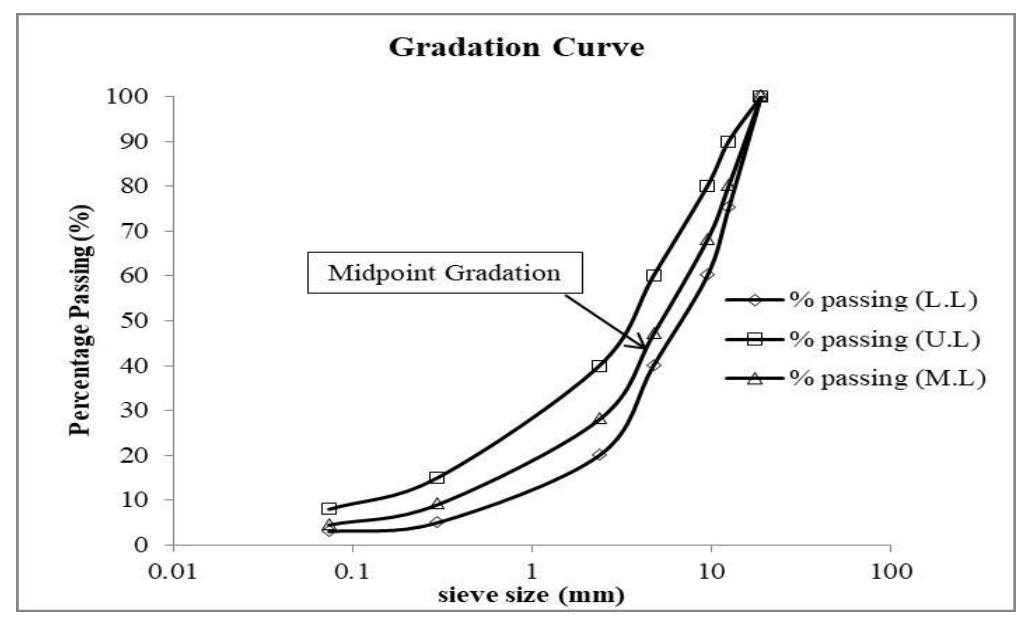

Figure 2. Aggregate gradation curve. 
Table 4. Optimum binder content (OBC).

\begin{tabular}{cc}
\hline Asphalt Sample with & OBC (\%) \\
\hline Base binder & 4.33 \\
$\mathbf{5 \%}$ CBNPs modified binder & 4.48 \\
$\mathbf{1 0} \%$ CBNPs modified binder & 4.63 \\
\hline
\end{tabular}

Generally an increase in the filler content in an asphalt mixture results in the reduction in the optimum binder content requirement for that mix because filler material acts as an 'extender' and requires less bitumen in order to fulfil the asphalt volumetric requirements [20]. However, researchers have experienced both an increase and decrease in the optimum binder content requirements while utilizing nano materials. Previous studies have shown that different fillers differently affect the properties of asphalt mixtures. Such changes in test properties can be associated with changes in viscosity of the filler-binder containing different fillers. However, it is difficult to get a direct correlation between filler-binder viscosity and compacted mixture properties. The reason for this could be attributed to the variable effects of different fillers on the compaction and volumetric properties of different asphalt mixtures [21].

An increase in optimum binder content was experienced with the increase in CBNPs dosage. Chelovian and Shafabakhsh [22] observed the same trend. An increase in optimum binder content requirement could be attributed to large surface area of CBNPs used in this study. This could also be attributed to the increase in viscosity of the binder after addition of the nano material. CBNPs, because of their small size, enhance the viscosity of bitumen making it stiffer. A higher viscosity leads to a thicker binder film of the modified bitumen in the mix thus increasing the binder volume in the mix [23].

\subsection{Tests Performed}

\subsubsection{Conventional Binder Tests}

Conventional binder tests; penetration, ductility and softening point were performed in conformity with ASTM D5-13, ASTM D113-99 and ASTM D36-76 respectively.

\subsubsection{Storage Stability}

The storage stability test was performed as per BS EN 13399 (2017). This technique was used to study CBNPs-modified asphalt binder's storage stability at high temperatures. CBNPs-modified asphalt binder was poured into a glass tube of $25 \mathrm{~mm}$ diameter and $140 \mathrm{~mm}$ height. The tube was placed vertically in an oven for $48 \mathrm{~h}$ at $163^{\circ} \mathrm{C}$ and then it was cooled in refrigerator at $-7^{\circ} \mathrm{C}$ for $4 \mathrm{~h}$. The tube was finally cut in three equal sections and, after melting the samples, a softening point test was performed for top and bottom portions. A difference of softening point less than $2.5^{\circ} \mathrm{C}$ is a widely used criterion for considering the blend to be stable at high temperatures [5].

\subsubsection{Performance Grading and Frequency Sweep Tests}

Performance grading and frequency sweep tests were performed in conformity with AASHTO T 315 using Anton Paar Dynamic Shear Rheometer (DSR). Pavement performance at high and intermediate temperatures can be assessed by using DSR [24]. Performance grading was carried out at $10 \mathrm{~Hz}$ frequency using $25 \mathrm{~mm}$ geometry and failure temperatures were recorded when $G^{*} / \sin \delta$ fell below $1 \mathrm{KPa}$.

The frequency sweep test was performed under strain controlled conditions at six different temperatures $\left(20^{\circ} \mathrm{C}, 30^{\circ} \mathrm{C}, 40^{\circ} \mathrm{C}, 50^{\circ} \mathrm{C}, 60^{\circ} \mathrm{C}\right.$ and $\left.70{ }^{\circ} \mathrm{C}\right) ; 8 \mathrm{~mm}$ and $25 \mathrm{~mm}$ plate geometries were used and with the gap of $2 \mathrm{~mm}$ and $1 \mathrm{~mm}$, respectively, between the parallel plates. Frequency was varied from $0.1 \mathrm{~Hz}$ to $10 \mathrm{~Hz}$ during the test; $10 \%$ strain limit was applied for base asphalt binder 
and $0.45 \%$ for CBNPs-modified asphalt binder. Rheological parameters; complex shear modulus $\left(G^{*}\right)$, rutting factor $\left(G^{*} / \sin \delta\right)$ and phase angle $(\delta)$ were determined.

\subsubsection{Bitumen Bond Strength Test}

Bitumen aggregate bond strength was studied by a Pneumatic Adhesion Tensile Testing Instrument (PATTI) in accordance with ASTM D 4541. Margalla limestone aggregate plate $\left(15^{\prime \prime} \times 6^{\prime \prime} \times 1.5^{\prime \prime}\right)$ was heated at $150{ }^{\circ} \mathrm{C}$ in the oven for one hour before the start of the test to remove all absorbed moisture. F-4 pullout stubs (0.5 inch diameter) were also heated for $30 \mathrm{~min}$ at $65^{\circ} \mathrm{C}$. Samples were tested after $24 \mathrm{~h}$ of dry conditioning and moisture conditioning. Pneumatic pressure was applied on the samples and burst pressure was recorded at which the stub was detached. The burst pressure was converted to pull-off tensile strength (POTS) by the equation given below. Five samples were tested for each category.

$$
\text { POTS }=\frac{(B P \times A g)-C}{A p s}
$$

where;

$B P=$ Burst pressure, $A g=$ Contact area of the gasket with the reaction plate, $C=$ Piston constant and Aps = Pullout stub area.

For F-4 stub type; $A g=4.06 \mathrm{in}^{2}, C=0.286 \mathrm{in}^{2}$ and $A p s=0.193 \mathrm{in}^{2}$.

\subsubsection{Cooper Wheel Tracking Test}

\section{Preparation of Specimen}

Slab specimens with dimensions $300 \mathrm{~mm} \times 300 \mathrm{~mm} \times 50 \mathrm{~mm}$ were used for the study. The material's weight that is required for slab manufacturing is determined on the basis of the volume of the mould and the required specific gravity $\left(G_{m b}\right)$. Temperature values maintained during the mixing and compaction operations were $158 \pm 5^{\circ} \mathrm{C}$ and $145 \pm 5^{\circ} \mathrm{C}$, respectively. Slab specimens were compacted using a Cooper Roller Compactor in four phases with 2.5, 3.5, 4.0 and 4.5 bar pressure. Trial specimens were used to calibrate for the required number of compactor passes. All the specimens achieved the required specific gravity at almost 10 passes per phase. Compacting head speed was controlled automatically on the basis of the required compaction effort (varies up to 10 cycles per min). Air voids of $5.5 \pm 0.5 \%$ were maintained during the compaction of the slabs.

\section{Sample Testing}

The test was performed in conformity with BS EN 12697-25. Slabs were placed in the Cooper Wheel Tracking equipment two hours before the start of test for temperature equilibrium. A load of $700 \mathrm{~N}$ was applied through the wheel at a frequency of $26.5 \mathrm{rpm}$. Tests were conducted at $40{ }^{\circ} \mathrm{C}$ and $55^{\circ} \mathrm{C}$ (under 10,000 loading cycles) in order to cover the temperatures encountered by pavements in Pakistan. Three samples were tested for each test condition.

\subsubsection{Dynamic Modulus Test}

\section{Sample Preparation}

Aggregates weighing $6500 \mathrm{~g}$ were used to prepare the cylindrical specimen (170 $\mathrm{mm}$ height and $150 \mathrm{~mm}$ diameter) using a Superpave Gyratory Compactor. Mixing of heated aggregates and asphalt binder was carried out at a temperature of $158 \pm 5^{\circ} \mathrm{C}$. Loose mixture was then placed in a flat pan for short-term conditioning as per AASHTO R-30. The compaction mould was preheated in the oven for $30 \mathrm{~min}$ and the mixture was brought to the compaction temperature of $145 \pm 5^{\circ} \mathrm{C}$ before placing in the Superpave Gyratory Compactor. A pressure of $600 \mathrm{kPa}$ was applied to the specimen while the internal 
angle of gyration was $1.16 \pm 0.02^{\circ}$. A target height of $170 \mathrm{~mm}$ was given as input to the machine and gyrations were applied by the machine until the desired height and $5.5 \pm 0.5 \%$ air voids content was achieved. A specimen of $101.6 \mathrm{~mm}$ diameter was cored from the compacted sample. The specimen was further trimmed to get $150 \mathrm{~mm}$ height for the dynamic modulus testing.

\section{Specimen Testing}

A Cooper NU-14 was used to determine the dynamic modulus of asphalt in accordance with AASHTO TP 62-03. Cylindrical specimens having $101.6 \mathrm{~mm}$ diameter and $150 \mathrm{~mm}$ height were placed in an environmental chamber to achieve the required temperature and then placed into the equipment frame for dynamic modulus analysis. Sinusoidal loading of $195 \mathrm{kPa}$ and $53 \mathrm{kPa}$ was applied to samples at $40{ }^{\circ} \mathrm{C}$ and $55{ }^{\circ} \mathrm{C}$ respectively at six different loading frequencies i.e., 25, 10, 5, 1, 0.5 and $0.1 \mathrm{~Hz}$. $195 \mathrm{kPa}$ and $53 \mathrm{kPa}$ is the midpoint of the dynamic stress levels provided in the standard for $40{ }^{\circ} \mathrm{C}$ and $55^{\circ} \mathrm{C}$ respectively Three samples were tested for each test condition.

\section{Results and Discussion}

\subsection{Conventional Asphalt Binder Properties}

The results of penetration, softening point and ductility tests of base asphalt binder and CBNPs-modified asphalt binder are presented in Table 5. Addition of CBNPs in base asphalt binder has decreased the penetration and ductility values whereas elevation in softening point has been observed. The resultant effect is more pronounced with the 10\% CBNPs content i.e., $24.5 \%$ reduction in penetration, $40 \%$ reduction in ductility and $12.5 \%$ increase in the softening point. Reduction in penetration along with ductility and increase in the softening point shows the increase in stiffness and decrease in high-temperature susceptibility by the introduction of CBNPs in asphalt binder. The large surface area of CBNPs and high degree of dispersion of CBNPs in the asphalt binder also influence the conventional properties. This indicates that the high-temperature performance of asphalt binder has been improved by incorporating CBNPs.

Table 5. Conventional testing results.

\begin{tabular}{cccc}
\hline \multirow{2}{*}{ Tests } & \multirow{2}{*}{ Base Asphalt Binder } & \multicolumn{2}{c}{ CBNPs Content (\%) } \\
\cline { 3 - 4 } & & $\mathbf{5}$ & $\mathbf{1 0}$ \\
\hline Penetration (1/10 of mm) & 61 & 53 & 46 \\
Softening Point $\left({ }^{\circ} \mathbf{C}\right)$ & 48 & 51.5 & 54 \\
Ductility (cm) & 100 & 75 & 60 \\
\hline
\end{tabular}

\subsection{Effect of CBNPs on Storage Stability of Asphalt Binder}

The difference in the softening point of the top and bottom sections of the test tube indicates the storage stability of CBNPs-modified bitumen. The results of the storage stability test are displayed in Table 6. Results indicate that difference of only $1{ }^{\circ} \mathrm{C}$ has been observed in case of $5 \%$ CBNPs content and $1.3{ }^{\circ} \mathrm{C}$ by incorporating $10 \%$ CBNPs content into asphalt binder. This indicates that $5 \%$ and $10 \%$ CBNPs content in asphalt binder meet the storage stability criteria i.e., the softening point difference should be less than $2.5^{\circ} \mathrm{C}$ for good high-temperature storage stability. Thus, CBNPs-modified asphalt binder is a stable material and can be utilized in road construction.

Table 6. Difference in softening point of CBNPs-modified bitumen.

\begin{tabular}{cccc}
\hline \multirow{2}{*}{ Softening Point $\left({ }^{\circ} \mathbf{C}\right)$} & Base Asphalt Binder & \multicolumn{2}{c}{ CBNPs Content (\%) } \\
\cline { 3 - 4 } & & $\mathbf{5}$ & $\mathbf{1 0}$ \\
\hline Top Portion & 49.5 & 52 & 54.4 \\
Bottom Portion & 49.9 & 53 & 55.7 \\
Difference & 0.4 & 1 & 1.3 \\
\hline
\end{tabular}




\subsection{Dynamic Shear Rheological Properties}

The effect of CBNPs on rheological parameters was studied by a frequency sweep test. The relationship between $G^{*}, \delta, G^{*} / \sin \delta$ and reduced frequency are shown in Figure $3 \mathrm{a}-\mathrm{c}$ at a reference temperature of $50{ }^{\circ} \mathrm{C}$. Figure 3 a shows that CBNPs-modified asphalt binder has higher $G^{*}$ values as compared to the base asphalt binder. Addition of 5\% CBNPs has increased stiffness at high temperatures/low frequencies and this effect became pronounced with the increase in CBNPs content to $10 \%$. This illustrates that asphalt binder turns stiffer and more resistant to permanent deformation at high temperatures by adding CBNPs. The large surface area of CBNPs and its homogenous dispersion in asphalt binder contribute towards the increase in $G^{*}$ value at high temperatures. Figure $3 \mathrm{~b}$ shows a gradual increase in phase angle values with the increase in temperature or decrease in loading frequency. The addition of CBNPs in asphalt binder has reduced the phase angle values at all loading frequencies and this reduction is more prominent at $10 \%$ CBNPs content. For instance at $10 \mathrm{~Hz}$ frequency, the values of the phase angle shifted from 83.44 degrees to 62.45 degrees by the addition of $10 \%$ CBNPs content. Thus, the results indicate that CBNPs have enhanced the elastic behaviour of the asphalt binder and have influenced the asphalt binder's rheology. It has also been reported in literature that carbon black-modified asphalt binder exhibits more elastic behaviour than conventional asphalt binders [5].

The rutting factor $\left(G^{*} / \sin \delta\right)$ can be related to resistance against permanent deformation and has been reported in the analysis of pavement performance at high temperatures [13]. Figure $3 c$ shows that $G^{*} / \sin \delta$ behaviour is similar to that of complex shear modulus $\left(G^{*}\right)$. Modified asphalt binders have shown higher rut resistance as compared to base asphalt binder. The high $G^{*} / \sin \delta$ value of modified binders is due to the increase in stiffness by addition of CBNPs. Thus, it can be stated that modifying asphalt binder with CBNPs effectively improves the resistance against rutting as well as the elastic behaviour of asphalt binder, making it suitable for high-temperature areas.

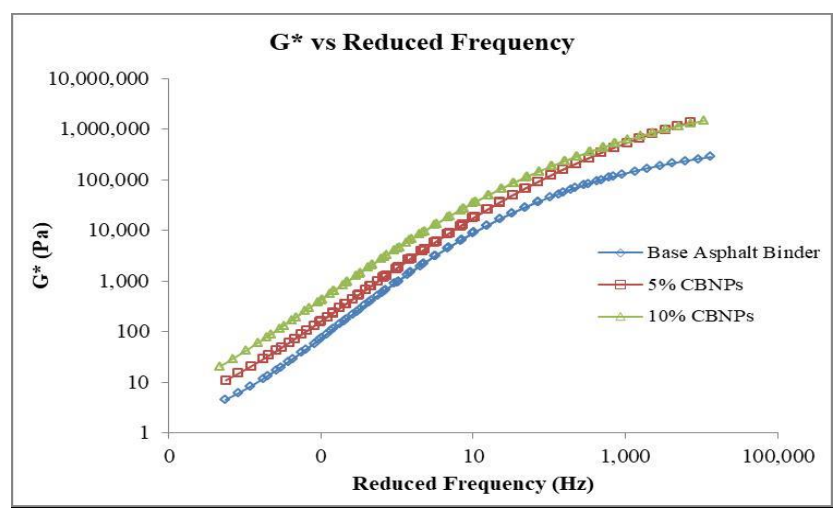

(a)

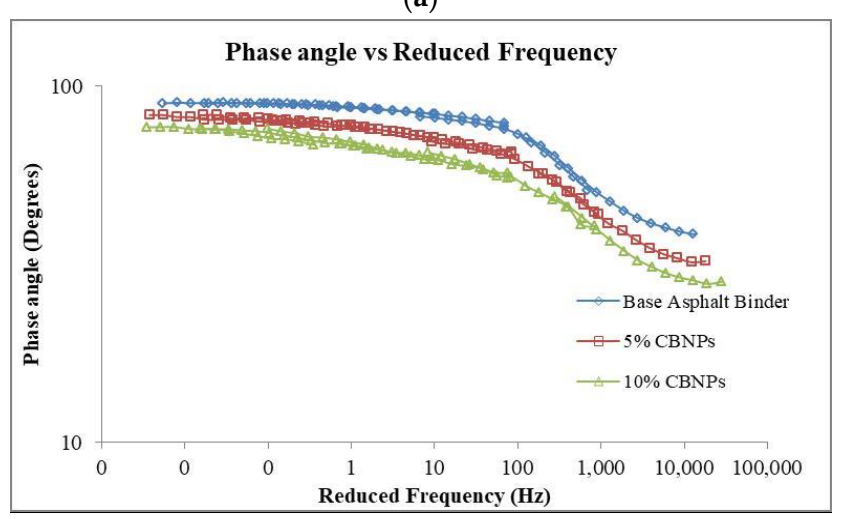

(b)

Figure 3. Cont. 


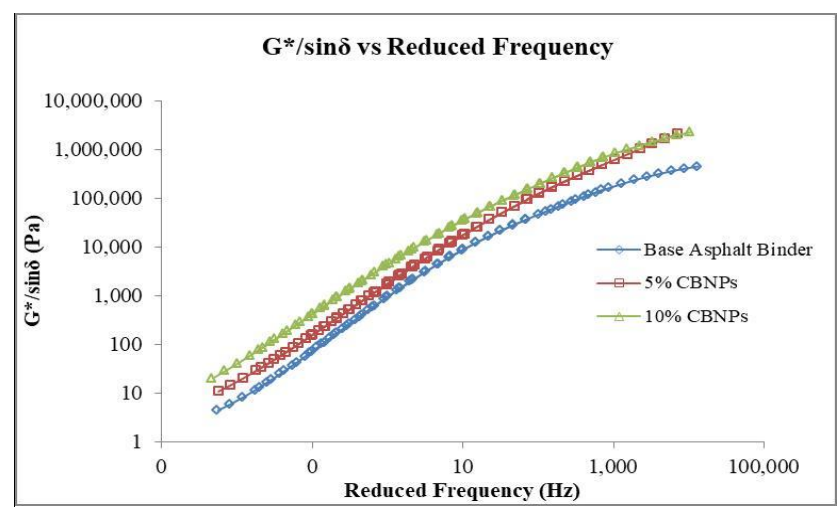

(c)

Figure 3. (a) Graphical representation of $G^{*}$ and reduced frequency; (b) graph of reduced frequency and phase angle; (c) graph of $G^{*} / \sin \delta$ versus reduced frequency.

\subsection{Performance Grading (PG) of CBNPs-Modified Asphalt Binder}

The effect of CBNPs on the high-temperature PG of asphalt binder is displayed in Table 7. According to the results, addition of 5\% CBNPs has changed the PG 58 to PG 64 by improving failure temperature from $62.5^{\circ} \mathrm{C}$ to $64.5^{\circ} \mathrm{C}$. Failure temperature has increased to $8.4^{\circ} \mathrm{C}$ by increasing the amount of CBNPs to $10 \%$ in the asphalt binder. The improvement in PG illustrates the enhanced pavement resistance against permanent deformation (rutting) by addition of CBNPs. Based on this, $10 \%$ CBNPs modified asphalt binder is suitable for pavement construction to meet the high-temperature requirements of Pakistan.

Table 7. Effect of CBNPs on the performance grade (PG).

\begin{tabular}{cc}
\hline Sample & Failure Temperatures $\left({ }^{\circ} \mathrm{C}\right)$ \\
\hline Base Asphalt Binder & $62.5($ PG 58$)$ \\
5\% CBNPs & $64.5($ PG 64) \\
10\% CBNPs & $70.9($ PG 70) \\
\hline
\end{tabular}

As mentioned earlier in the problem statement, flexible pavements at high temperature are more susceptible to mix rutting which becomes the cause of their premature failure. Due to extreme hot weather conditions, the premature failure of flexible pavements is the major problem faced by the pavement industry in Pakistan. According to temperature zoning done by Mirza et al. [17], PG 70-10 is considered suitable for most parts of the country. High-temperature areas in Pakistan are problematic, whereas in winters temperature hardly goes below $0{ }^{\circ} \mathrm{C}$. It has been observed that base binder (PG-58-22) is more sensitive to temperature than PG 70-10. Therefore, it has been evaluated that high PG values obtained at 10\% CBNPs dosage are more suitable.

\subsection{Effect of CBNPs on Bitumen Aggregate Bond Strength}

The effect of CBNPs on bitumen aggregate bond strength was studied using a pneumatic adhesion tensile testing instrument (PATTI) and the results are displayed in Table 8a,b. Figure 4 shows the comparison of POTS after $24 \mathrm{~h}$ of dry and moisture conditioning in the form of a bar chart. Samples modified with CBNPs have higher POTS values than the base asphalt binder after $24 \mathrm{~h}$ of dry and moisture conditioning. The addition of CBNPs has increased the POTS value from 7.5 MPa to $17 \mathrm{MPa}$ after $24 \mathrm{~h}$ of dry conditioning. The mode of failure is cohesive (breakage of bond at bitumen-bitumen interface) post $24 \mathrm{~h}$ of dry conditioning and changed to adhesive failure (breakage of bond at bitumen-aggregate interface) after $24 \mathrm{~h}$ of moisture conditioning. The change of failure mode could be attributed to water penetration through the aggregate (porous material) which weakens 
the bond at the bitumen-aggregate interface and results in low pull-off tensile strength values [25]. After $24 \mathrm{~h}$ of moisture conditioning, modified binders performed better than the base binder and $10 \%$ CBNPs-modified binder has shown the highest POTS values. Addition of nano material has increased the wetting potential of the modified binder promoting better wetting of the bitumen onto the aggregate surface, thus enhancing the bitumen-aggregate bond strength. This could also be attributed to the increase in stiffness of the asphalt binder because of the addition of nano particles [26]. Moreover, significant improvement in bond strength of a nano-hybrid material could be attributed to hydrogen bonds and van der Waals interaction [27].

According to these results, it can be concluded that CBNPs have the potential to improve the adhesive/cohesive bond strength of asphalt.

Table 8. (a) Pull-off tensile strength (POTS) values (MPa) and failure modes after $24 \mathrm{~h}$ of dry conditioning. (b) POTS values (MPa) and failure modes after $24 \mathrm{~h}$ of moisture conditioning.

\begin{tabular}{cccc}
\hline \multirow{2}{*}{ Replicates } & \multicolumn{3}{c}{ 24 h Dry Conditioning } \\
\cline { 2 - 4 } & Base Asphalt Binder & $\mathbf{5 \%}$ CBNPs & $\mathbf{1 0 \%}$ CBNPs \\
\hline $\mathbf{1}$ & $7.67(C)$ & $11.80(C)$ & $16.54(C / A)$ \\
$\mathbf{2}$ & $8.00(C)$ & $11.80(C)$ & $16.50(C)$ \\
$\mathbf{3}$ & $7.67(C)$ & $12.00(C)$ & $16.73(C)$ \\
$\mathbf{4}$ & $7.11(C)$ & $12.00(C)$ & $17.34(C)$ \\
$\mathbf{5}$ & $6.82(C)$ & $11.80(C)$ & $17.80(C)$ \\
Average & 7.50 & 11.90 & 17.00 \\
\hline
\end{tabular}

$C=$ Cohesive failure and $C / A=50 \%$ Cohesive and $50 \%$ Adhesive failure.

(a)

\begin{tabular}{cccc}
\hline \multirow{2}{*}{ Replicates } & \multicolumn{3}{c}{ 24 h Moisture Conditioning } \\
\cline { 2 - 4 } & Base Asphalt Binder & $\mathbf{5 \%} \mathbf{C B N P s}$ & $\mathbf{1 0 \%} \mathbf{C B N P s}$ \\
\hline $\mathbf{1}$ & $6.55(A)$ & $10.53(C / A)$ & $15.43(A)$ \\
$\mathbf{2}$ & $6.80(A)$ & $10.53(A)$ & $15.37(A)$ \\
$\mathbf{3}$ & $6.55(A)$ & $10.50(A)$ & $15.43(A)$ \\
$\mathbf{4}$ & $6.42(A)$ & $10.69(A)$ & $16.20(A)$ \\
$\mathbf{5}$ & $6.42(A)$ & $10.69(A)$ & $14.48(A)$ \\
Average & 6.55 & 10.60 & 15.40 \\
\hline
\end{tabular}

$C / A=50 \%$ Cohesive and 50\% Adhesive failure and $A=$ Adhesive failure.

(b)

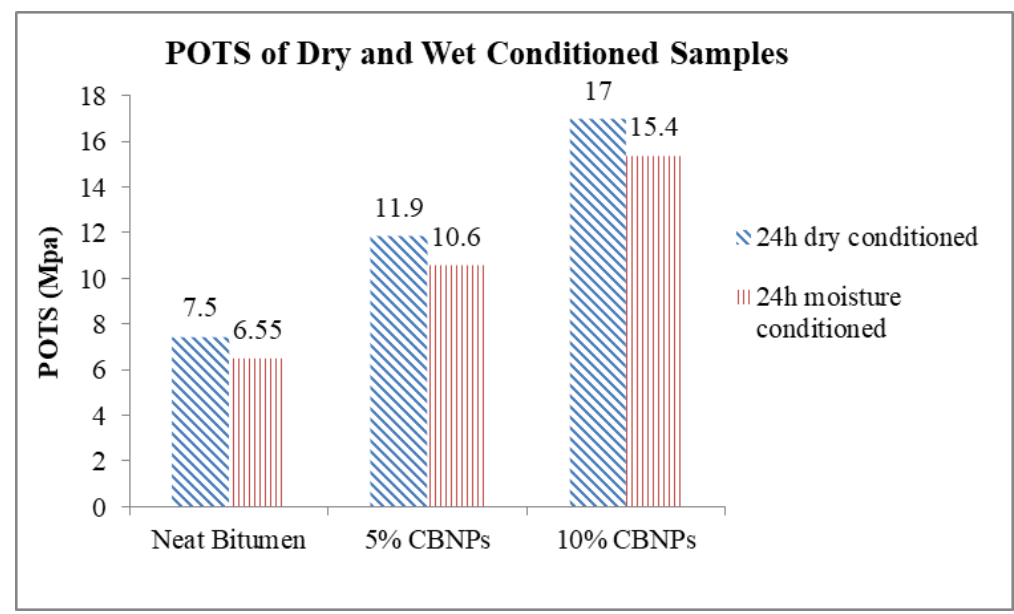

Figure 4. POTS of dry and moisture-conditioned samples. 


\subsection{Study of CBNPs Effect on Rut Depth}

A wheel tracking test was performed to study the effect of CBNPs on the rut depth. Graphs between number of wheel passes and rut depth at $40{ }^{\circ} \mathrm{C}$ and $55^{\circ} \mathrm{C}$ are shown in Figure $5 \mathrm{a}, \mathrm{b}$. Base asphalt showed the highest rut depth values against the standard 10,000 wheel passes. Addition of 5\% CBNPs reduced the rut depth to $3 \mathrm{~mm}$ and $5.6 \mathrm{~mm}$ at $40{ }^{\circ} \mathrm{C}$ and $55{ }^{\circ} \mathrm{C}$ respectively (after 10,000 wheels passes). Furthermore, $10 \%$ CBNPs-modified asphalt has shown the maximum reduction in rut depth at both temperatures and after 10,000 passes i.e., $20 \%$ reduction at $40{ }^{\circ} \mathrm{C}$ and $37.8 \%$ reduction at $55^{\circ} \mathrm{C}$. Nano-particles increase the surface area of the asphalt binder and may enhance the interaction within the asphalt which results in more resistance against rutting [28]. Zhao et al. experienced an increase in rutting resistance when nano-carbon black modified asphalt was subjected to 8000 loading cycles during an asphalt pavement analyzer rutting test. This illustrates that CBNPs successfully enhances the high-temperature performance of asphalt by increasing its resistance against rutting.

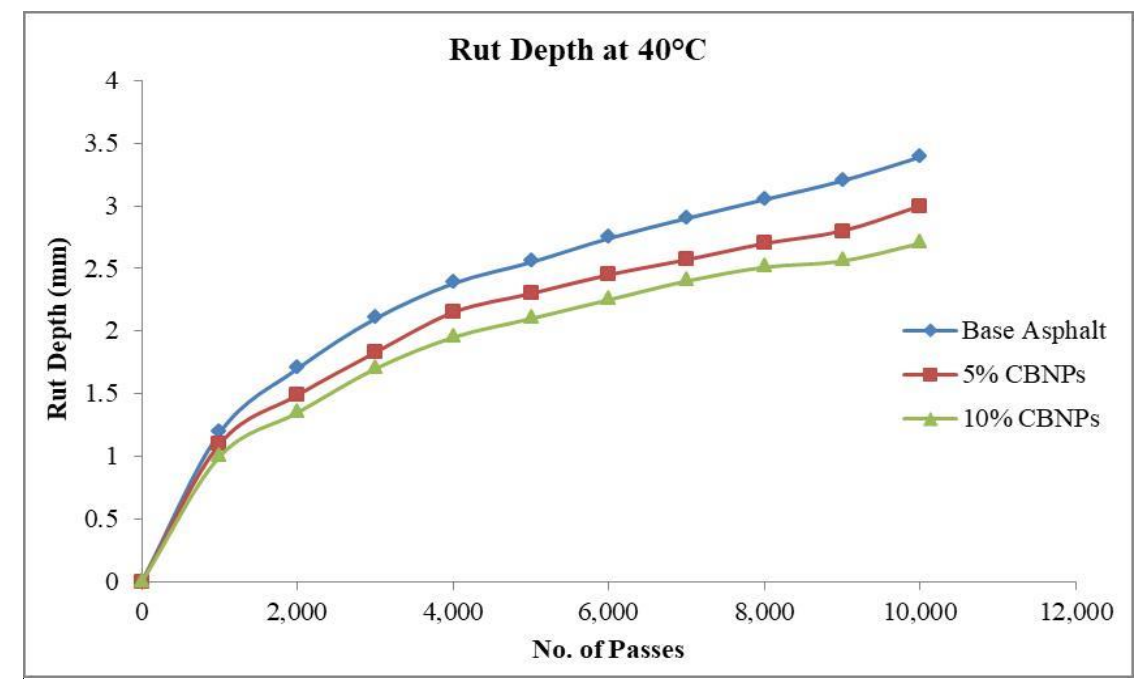

(a)

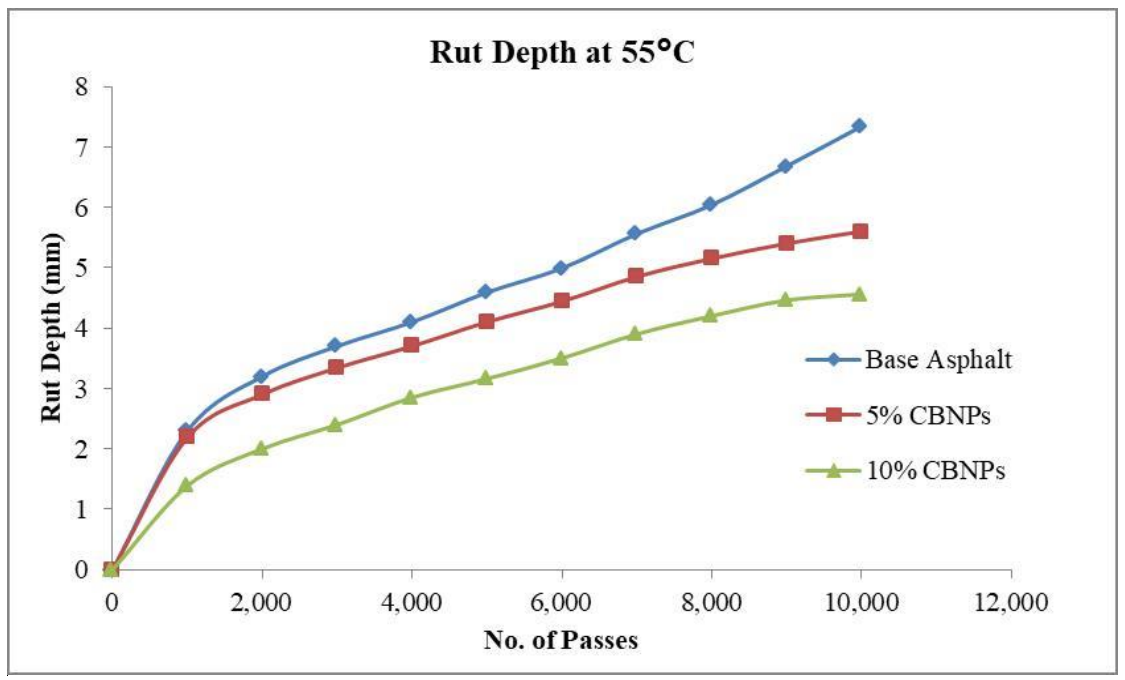

(b)

Figure 5. (a) Graph of rut depth and number of passes at $40{ }^{\circ} \mathrm{C}$; (b) graph of rut depth and number of passes at $55^{\circ} \mathrm{C}$. 


\subsection{Effect of CBNPs on Dynamic Modulus of Asphalt}

The dynamic modulus indicates the stiffness of asphalt and can be used as a measure to study the resistance of asphalt against permanent deformation. The higher the dynamic modulus value, the higher the resistance against permanent deformation. Figure $6 a, b$ show the relationship of dynamic modulus with loading frequency at $40{ }^{\circ} \mathrm{C}$ and $55{ }^{\circ} \mathrm{C}$. As shown, the dynamic modulus of asphalt decreases with the decrease in loading frequency and increase in temperature. This is due the fact that asphalt is temperature-dependent and becomes soft with an increase in temperature which leads to a decrease in dynamic modulus [29]. Modified samples have greater values of dynamic modulus than the base asphalt samples. Moreover, 10\% CBNPs-modified asphalt has shown the highest dynamic modulus values at $40{ }^{\circ} \mathrm{C}$ and $55^{\circ} \mathrm{C}$ and at all loading frequencies. Nano-modified asphalt binder creates more contact forces with aggregate particles. Scattered nano-particles fill the gap between the aggregates which induces an improvement in dynamic modulus of asphalt and rutting resistance as well [28]. Hence, CBNPs have proven to be a promising modifier for enhancing the high-temperature performance of asphalt.

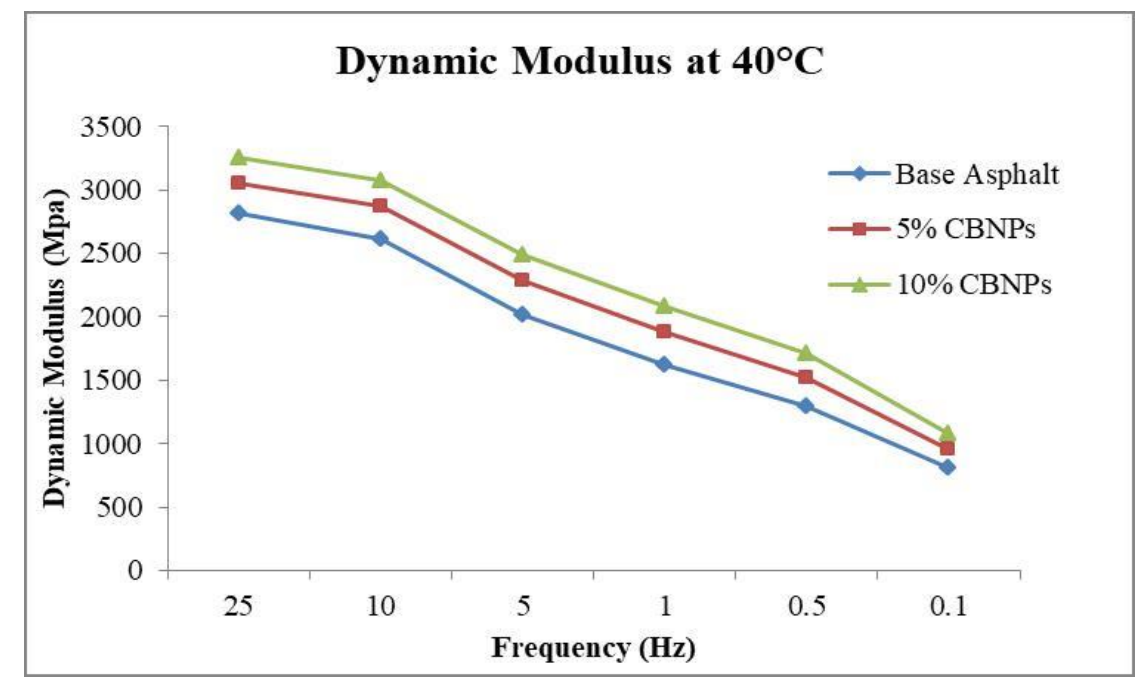

(a)

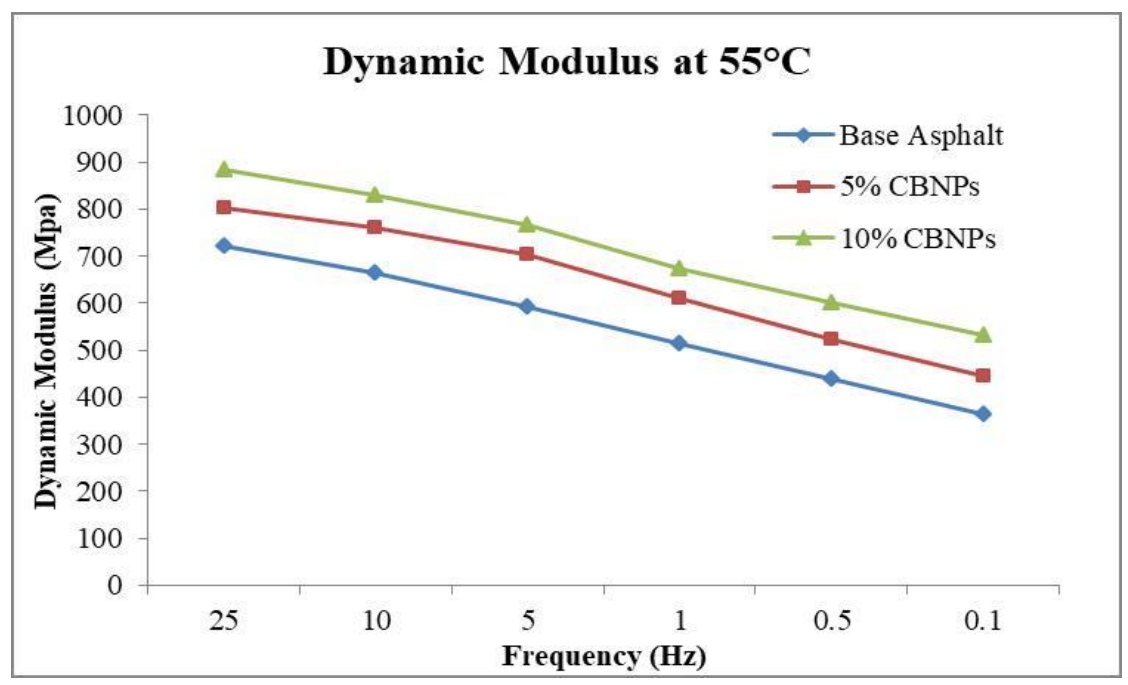

(b)

Figure 6. (a) Graph of dynamic modulus and frequency at $40{ }^{\circ} \mathrm{C} ;(\mathbf{b})$ graph of dynamic modulus and frequency at $55^{\circ} \mathrm{C}$. 
According to the Federal Highway Administration (FHWA), the structural and functional capacity of a pavement and its useful service life are key performance indicators and greatly impact the overall sustainability of a pavement [30]. This is because improved pavement performance leads to lower maintenance costs and longer service life, consequently conserving resources. It can be concluded from the results of the CBNPs-modified asphalt's performance testing that the addition of CBNPs in asphalt could help in building sustainable pavements.

\section{Conclusions}

The following conclusions have been drawn through careful analysis of the test results:

1. Addition of carbon black nano-particles has enhanced the conventional asphalt binder properties. For instance, $10 \%$ CBNPs content in conventional binder has reduced the penetration and ductility value by $24.5 \%$ and $40 \%$, respectively. Furthermore, an elevation in softening point has been observed by the addition of CBNPs which leads to the reduction in high-temperature susceptibility of the asphalt binder. The large surface area of CBNPs and high degree of dispersion has contributed towards the change in the conventional asphalt binder properties, especially the stiffness of the binder.

2. A storage stability test has been used to check the permanence of the dispersion of CBNPs in the asphalt binder through identifying the difference in softening points of the samples obtained from the top and bottom sections of the test tube. The difference in softening point that has been obtained during the test is less than $2.5^{\circ} \mathrm{C}$ i.e., $1^{\circ} \mathrm{C}$ and $1.3^{\circ} \mathrm{C}$ for $5 \%$ and $10 \%$ CBNPs-modified binder, respectively. This confirms that CBNPs-modified asphalt binder is a stable material and can be utilized by the pavement construction industry.

3. The complex shear modulus and performance grade of asphalt binder is significantly enhanced by incorporating CBNPs. Addition of $10 \%$ CBNPs has increased the complex shear modulus values from $8847 \mathrm{~Pa}$ to $34,679 \mathrm{~Pa}$ at $10 \mathrm{~Hz}$ frequency and $50{ }^{\circ} \mathrm{C}$ temperature. Also, $10 \% \mathrm{CBNPs}$ addition has changed the PG 58 to PG 70 by improving the failure temperature from $62.5^{\circ} \mathrm{C}$ to $70.9^{\circ} \mathrm{C}$. The large surface area of CBNPs and its homogenous dispersion influences the asphalt binder's rheology and helps achieve the desired stiffness improvement. Thus, it can be concluded that CBNPs is a promising modifier when it comes to improving resistance against permanent deformation.

4. Bitumen bond strength test results show significant improvement in the cohesive and adhesive bond strength of the binder through the incorporation of CBNPs. During $24 \mathrm{~h}$ of dry conditioning, and moisture conditioning, addition of 10\% CBNPs has increased the POTS values from 7.5 MPa to $17 \mathrm{MPa}$ and $6.55 \mathrm{MPa}$ to $15.40 \mathrm{MPa}$ respectively. The increase in adhesive and cohesive bond strength could be attributed to the electrostatic contribution in nano-modified material. The addition of nano material has increased the wetting potential of the modified binder promoting better wetting of the bitumen on to the aggregate surface thus enhancing the bitumen-aggregate bond strength. This could also be attributed to the increase in stiffness of the asphalt binder because of addition of nano particles [26].

5. Bond strength is an important parameter in measuring the ability of asphalt binder to withstand moisture damage. Tests that are carried out directly on different bitumen-aggregate combinations after moisture conditioning can efficiently measure their moisture sensitivity [31]. Moisture sensitivity directly affects the durability of an asphalt mixture [32]. Significant improvement in POTS after $24 \mathrm{~h}$ of moisture conditioning shows that CBNPs have the potential to improve the durability of asphalt.

6. CBNPs have clearly shown potential for improving the permanent deformation resistance of the modified asphalt mixture. During a wheel tracking test, almost $37.8 \%$ reduction in rut depth at $55{ }^{\circ} \mathrm{C}$, and $20 \%$ reduction in rut depth at $40{ }^{\circ} \mathrm{C}$ has been observed through the addition of $10 \%$ CBNPs in asphalt. Dynamic modulus values at $40{ }^{\circ} \mathrm{C}$ and $55^{\circ} \mathrm{C}$ have been observed to be 
enhanced by introducing CBNPs. For instance, at $10 \mathrm{~Hz}$ and $55{ }^{\circ} \mathrm{C}, \mathrm{CBNPs}$ have increased the dynamic modulus values from $664.4 \mathrm{MPa}$ to $830.67 \mathrm{MPa}$. The improvement in dynamic modulus and improved rutting resistance is due to the fact that CBNPs-modified asphalt binder has higher stiffness and a better ability to bond with the aggregates.

CBNPs produced by perennial mountain trees (a natural source) have been used in this study to modify base asphalt binder properties. Similar natural resources are easily available in the country and it would be easy for it to utilize CBNPs in asphalt pavements. It has been found in the literature that CBNPs can effectively improve asphalt pavement performance at $15 \%$ or $20 \%$ dosage $[12,14,33]$, while the CBNPs used in this study have $10 \%$ desirable dosage in asphalt. Thus, the CBNPs produced through natural sources have more potential to influence the asphalt properties and can help in conserving resources. As the raw material (perennial mountain trees) is a natural source and it is required in lesser quantity, the production and utilization of CBNPs in the pavement industry can also prove beneficial from an economic point of view as well. The high-temperature performance of asphalt binder is found to be considerably enhanced by incorporating CBNPs. Moreover, it has also improved the cohesive and adhesive bond strength of the asphalt binder, making it a strong candidate to be used as a modifier.

Any modifier gifted with the dual capability of promoting adhesion and the rheological properties of the asphalt, would be considered ideal for most pavement industry applications. CBNPs seem to have this potential, which could help address the problems of the local pavement construction industry.

Author Contributions: The idea was conceived by N.A. The methodology was proposed by J.R. and M.A.K. Experimental work was performed by J.R., M.H. and M.F.u.H. Results were analyzed by J.R., M.A.K., N.A., M.H., S.A.A. and M.F.u.H. The paper was written by J.R. The paper was reviewed and edited by M.A.K., N.A., S.B.A.Z., S.A.A. and F.S. All authors approved and studied the final paper.

Funding: This research received no external funding.

Acknowledgments: The authors thank Muhammad Ali Nasir for his support and guidance.

Conflicts of Interest: The authors declare no conflict of interest.

\section{References}

1. Abtahi, S.M.; Sheikhzadeh, M.; Hejazi, S.M. Fiber-reinforced asphalt-concrete-A review. Constr. Build. Mater. 2010, 24, 871-877. [CrossRef]

2. Rostler, F.S.; White, R.M.; Dannenberg, E.M. Carbon black as a reinforcing agent for asphalt. In Proceedings of the Association of Asphalt Paving Technologists Proc, San Antonio, TX, USA, 21-23 February 1977; Volume 46, pp. 376-410.

3. Khosla, N.P. Effect of the use of modifiers on performance of asphaltic pavements. Transpor. Res. Rec. 1991, 1317.

4. Yao, Z.; Monismith, C.L. Behaviour of Asphalt Mixtures With Carbon Black Reinforcement (With Discussion). In Proceedings of the Association of Asphalt Paving Technologists Proc, St. Paul, MN, USA, 1986; Volume 55, pp. 564-585.

5. Feng, Z.; Rao, W.; Chen, C.; Tian, B.; Li, X.; Li, P.; Guo, Q. Performance evaluation of bitumen modified with pyrolysis carbon black made from waste tyres. Constr. Build. Mater. 2016, 111, 495-501. [CrossRef]

6. Ahmedzade, P.; Geckil, T. Influence of carbon black on the mechanical and electrical properties of asphalt mixtures. Indian J. Eng. Mater. Sci. 2007, 14, 358-364.

7. Rodgers, W.J.; Gunay, B.; Woodside, A. Rheological and electrical properties of modified bitumen. Proc. Inst. Civ. Eng. Transp. 2010, 163, 175-182. [CrossRef]

8. Martin, K.G. Preliminary microviscometer studies of carbon black/rubber/bitumen dispersions. In Proceedings of the Australian Road Research Board (ARRB) Conference, Canberra, Australia, 1962; Volume 1, pp. 895-911.

9. Park, T.; Lovell, C.W. Using pyrolized carbon black (PCB) from waste tires in asphalt pavement (part 1, limestone aggregate). Jt. Transp. Res. Progr. 1996, 222. [CrossRef]

10. Chebil, S.; Chaala, A.; Roy, C. Use of softwood bark charcoal as a modifier for road bitumen. Fuel 2000, 79, 671-683. [CrossRef] 
11. Zhang, J.; Wang, J.; Wu, Y.; Wang, Y.; Wang, Y. Evaluation of the improved properties of SBR/weathered coal modified bitumen containing carbon black. Constr. Build. Mater. 2009, 23, 2678-2687. [CrossRef]

12. Li, C.; Fan, Z.; Wu, S.; Li, Y.; Gan, Y. Effect of carbon black nanoparticles from the pyrolysis of discarded tires on the performance of asphalt and its mixtures. Appl. Sci. 2018, 8, 624. [CrossRef]

13. Cong, P.; Xu, P.; Chen, S. Effects of carbon black on the anti aging, rheological and conductive properties of SBS/asphalt/carbon black composites. Constr. Build. Mater. 2014, 52, 306-313. [CrossRef]

14. Bai, B.C.; Park, D.-W.; Vo, H.V.; Dessouky, S.; Im, J.S. Thermal Properties of Asphalt Mixtures Modified with Conductive Fillers. J. Nanomater. 2015, 16, 255. [CrossRef]

15. Zhao, S.; Huang, B.; Shu, X.; Ye, P. Laboratory Investigation of Biochar-Modified Asphalt Mixture. Transp. Res. Rec. 2014, 2445, 56-63. [CrossRef]

16. Mirbaha, B.; Abdi, A.; Zarei, M.; Zarei, A.; Akbari nia, F. Experimental determination of the optimum percentage of asphalt mixtures reinforced with Nano-carbon black and polyester fiber industries. Eng. Solid Mech. 2017, 5, 285-292. [CrossRef]

17. Mirza, M.W.; Abbas, Z.; Rizvi, M.A. Temperature Zoning of Pakistan for Asphalt Mix Design. Pak. J. Eng. Appl. Sci. 2011, 8, 49-60.

18. Hussan, S.; Kamal, M.A.; Hafeez, I.; Farooq, D.; Ahmad, N.; Khanzada, S. Statistical evaluation of factors affecting the laboratory rutting susceptibility of asphalt mixtures. Int. J. Pavement Eng. 2017, 1-15. [CrossRef]

19. Faramarzi, M.; Golestani, B.; Lee, K.W. Improving moisture sensitivity and mechanical properties of sulfur extended asphalt mixture by nano-antistripping agent. Constr. Build. Mater. 2017, 133, 534-542. [CrossRef]

20. Huang, B.; Shu, X.; Chen, X. Effects of mineral fillers on hot-mix asphalt laboratory-measured properties. Int. J. Pavement Eng. 2007, 8, 1-9. [CrossRef]

21. Kallas, B.F.; Puzinauskas, V.P.; Krieger, H.C. Mineral Fillers in Asphalt Paving Mixtures. Highw. Res. Board Bull. $1962,329$.

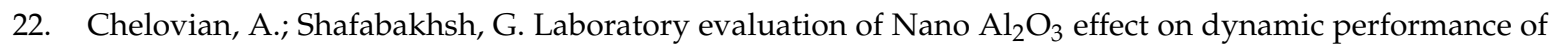
stone mastic asphalt. Int. J. Pavement Res. Technol. 2017, 10, 131-138. [CrossRef]

23. Hussain, M.H.M.; Ghaly, N.F.; Ibrahim, I.M. Modified Hot Mix Asphalt for Road Maintenance. World Appl. Sci. J. 2008, 5, 236-245.

24. Zaniewski, J.P.; Pumphrey, M.E. Evaluation of Performance Graded Asphalt Binder Equipment and Testing Protocol. Asph. Technol. Progr. 2004, 107.

25. Moraes, R.; Velasquez, R.; Bahia, H. Measuring the Effect of Moisture on Asphalt-Aggregate Bond with the Bitumen Bond Strength Test. Transp. Res. Rec. 2011, 2209, 70-81. [CrossRef]

26. Bahia, H.; Moraes, R.; Velasquez, R. The Effect of Bitumen Stiffness on the Adhesive Strength Measured by the Bitumen Bond Strength Test. In Proceedings of the 5th Eurasphalt and Eurobitume Congress, Istanbul, Turkey, 2012.

27. Valadares, L.F.; Linares, E.M.; Bragança, F.C.; Galembeck, F. Electrostatic adhesion of nanosized particles: The cohesive role of water. J. Phys. Chem. C 2008, 112, 8534-8544. [CrossRef]

28. Yao, H.; You, Z. Effectiveness of Micro- and Nanomaterials in Asphalt Mixtures through Dynamic Modulus and Rutting Tests. J. Nanomater. 2016, 2016, 10. [CrossRef]

29. Li, P.; Zheng, M.; Wang, F.; Che, F.; Li, H.; Ma, Q.; Wang, Y. Laboratory Performance Evaluation of High Modulus Asphalt Concrete Modified with Different Additives. Adv. Mater. Sci. Eng. 2017, 2017. [CrossRef]

30. Van Dam, T.J.; Harvey, J.T.; Muench, S.T.; Smith, K.D.; Snyder, M.B.; Al-Qadi, I.L.; Ozer, H.; Meijer, J.; Ram, P.V.; Roesler, J.R.; et al. Chapter 5. Construction Considerations to Improve Pavement Sustainability. In Towards Sustainable Pavement Systems: A Reference Document; US Department of Transportation, Federal Highway Administration: Washington, DC, USA, 2015.

31. Canestrari, F.; Cardone, F.; Graziani, A.; Santagata, F.A.; Bahia, H.U. Adhesive and cohesive properties of asphalt-aggregate systems subjected to moisture damage. Road Mater. Pavement Des. 2010, 11, 11-32. [CrossRef] 
32. Behiry, A.E.A.E.M. Laboratory evaluation of resistance to moisture damage in asphalt mixtures. Ain Shams Eng. J. 2013, 4, 351-363. [CrossRef]

33. Zarei, M.; Zahedi, M. Effect of nano carbon black on mechanical properties of asphalt mixtures. J. Fundam. Appl. Sci. 2016, 8, 2996-3008. 